\title{
Marine algae Sargassum horneri bioactive factor suppresses proliferation and stimulates apoptotic cell death in human breast cancer MDA-MB-231 cells in vitro
}

\author{
Masayoshi Yamaguchi ${ }^{*}$ and Toru Matsumoto ${ }^{2}$ \\ ${ }^{1}$ Department of Hematology and Medical Oncology, Emory University School of Medicine, Atlanta, USA \\ ${ }^{2}$ Biomaterial Department, Maruhachi Muramatsu, Inc., Yaizu, Japan
}

\begin{abstract}
Marine algae Sargassum horneri (S. horneri) bioactive factor has been shown to possess anabolic bone effects due to stimulating osteblastic bone formation and suppressing osteoclastogenes. However, the effects of $S$. horneri on cancer cell bone metastasis have not been investigated. This study was undertaken to determine the effects of $S$. horneri bioactive component on human breast cancer MDA-MB-231 bone metastatic cells in vitro. Proliferation of MDA-MB-231 cells was suppressed by culture with $S$. horneri active component (less than 3000 molecular weight; $10-200 \mu \mathrm{g} / \mathrm{ml}$ ) for 5 and 10 days. $S$. horneri active component was suggested to inhibit G1 and G2/M phase cell cycle arrest in MDA-MB-231 cells using inhibitors of cell-cycle arrest. Moreover, $S$. horneri active component stimulated apoptotic cell death. This effect was prevented in the presence of caspase-3-inhibitor. Thus, $S$. horneri active component was found to suppress cell proliferation and stimulate apoptotic cell death in human breast cancer MDA-MB-231 bone metastatic cells in vitro, demonstrating an anticancer effect.
\end{abstract}

\section{Introduction}

Breast cancer is by far the most common cancer in women worldwide, and it is associated with a variety of lifestyle choice, such as obesity, later onset of first childbirth, and the use of hormone replacement therapy [1]. Breast cancer still remains the second cause of cancer death in the developed world. Breast cancer bone metastasis occurs in $70-80 \%$ of patients with advanced breast cancer, leading to severe pathological bone fractures, pain, hypercalcemia, and spinal cord and nerve-compression syndromes, which are a common cause of morbidity and mortality. Chemoprevention is the use of drugs, vitamins, food supplements, vaccines, or other agents to reduce the risk, delay of the development or recurrence of cancer [1,2].

Among marine algae of Undaria pinnatifida, Sargassum horneri, Eisenia bicyclis, Cryptonemia scmitziana, Gelidium amansii, and Ulva pertusa Kjellman, which were gathered seasonally, Sargassum horneri (S. horneri) has been found to possess a unique anabolic effect on bone metabolism [3]. S. horneri extract possessed a stimulatory effect on osteoblastic bone formation and an inhibitory effect on osteoclastic bone resorption in vitro, thereby increasing bone mass [4-7]. Intake of $S$. horneri extract was found to prevent bone loss in osteoporosis animal models and in healthy human [8-10]. Functional food factor $S$. horneri extract may be usefulness as an osteogenic factor in preventing osteoporosis in human subjects. Moreover, S. horneri active component may possess a suppressive effect on bone loss induced by breast cancer cell bone metastasis that is occurred extremely high in breast cancer patients [11-15]. However, this has not been investigated.

This study was undertaken to determine whether S. horneri active component possesses anticancer effects using human breast cancer MDA-MB-231 bone metastatic cells in vitro model. We found that $S$. horneri active component suppresses proliferation and stimulates apoptotic cell death of human breast cancer MDA-MB-231 bone metastatic cells. This finding suggests that the intake of $S$. horneri active component is a useful tool in the prevention and therapy of breast cancer bone metastasis.

\section{Materials and methods}

\section{Materials}

Dulbecco's Modification of Eagle's Medium (DMEM) with $4.5 \mathrm{~g} / \mathrm{L}$ glucose, L-glutamine and sodium pyruvate and antibiotics (penicillin and streptomycin; P/S) were purchased from Invitrogen Corp. (Carlsbad, CA). Fetal bovine serum (FBS) was from HyClone (Logan, UT). Sodium butyrate, roscovitine, sulforaphane, caspase- 3 inhivitor and other all reagents were purchased from Sigma-Aldrich (St. Louis, $\mathrm{MO})$ unless otherwise specified.

\section{S. horneri active component}

Marine algae S. horneri [Sargassum horneri (Turner) C. Agardh] was seasonally gathered from the coast at Shimoda (Shizuoka Prefecture, Japan) and Miyako (Iwate Prefecture, Japan), and it was freeze-dried and powered [4]. The gathered fresh marine algae were homogenized in distilled water and are centrifuged at $5500 \mathrm{~g}$ in a refrigerated

Correspondence to: Masayoshi Yamaguchi, Ph.D, Department of Hematology and Medical Oncology, Emory University School of Medicine, 1365 C Clifton Road, NE, Atlanta, GA 30322, USA; E-mail: yamamasa1155@yahoo.co.jp

Key words: Sargassum horneri, breast cancer MDA-MB-231 cells, cell proliferation, apoptosis

Received: March 01, 2015; Accepted: March 14, 2015; Published: March 17, 2015 
centrifuge for 10 minutes. The $5500 \mathrm{~g}$ supernatant fraction was pooled for freeze-drying. The powder of the water-solubilized extract was dissolved in ice-cold distilled water for use in the experiments. The water-solubilized extract from $S$. horneri was purified by the method of membrane fractionation to collect the active component less than $3000 \mathrm{MW}[4]$.

\section{Human breast cancer MDA-MB-231-bone metastatic cells}

Human breast cancer MDA-MB-231 bone metastatic cells (MDAMB-231) lack estrogen, progesterone and human epithelial growth factor type 2 (HER2) receptors [16], and are therefore considered as triple negative. They express high levels of the epithelial growth factor receptor (EGFR) and activation of this receptor and its downstream signaling events enhance migration, proliferation, invasion, and progression of the malignant phenotype of these cells [16]. We used the estrogen-independent bone-seeking triple negative human breast cancer MDA-MB-231 cells. This cell line was obtained from the American Type Culture Collection (Rockville, MD, USA).

\section{Cell proliferation}

Breast cancer MDA-MB-231 cells ( $1 \times 10^{5} / \mathrm{ml}$ per well) were cultured in a 24 -well plate in DMEM containing $10 \%$ FBS and $1 \% \mathrm{P} / \mathrm{S}$ in the presence or absence of $S$. horneri active component (less than $3000 \mathrm{MW} ; 10,25,50,100$ or $200 \mu \mathrm{g} / \mathrm{ml}$ ) for 5 and 10 days in a watersaturated atmosphere containing $5 \% \mathrm{CO}_{2}$ and $95 \%$ air at $37^{\circ} \mathrm{C}$. In separate experiments, MDA-MB-231 cells were cultured for 3 days in the presence or absence of $S$. horneri active component $(50 \mu \mathrm{g} / \mathrm{ml})$ with or without sodium butyrate $(10$ and $100 \mu \mathrm{M})$, roscovitine $(10$ and 100 $\mathrm{nM}$ ) or sulforaphane (1 and $10 \mathrm{nM})$. After culture, cells were detached from each culture dishes and counted [17].

\section{Apoptotic cell death}

Breast cancer MDA-MB-231 cells $\left(1 \times 10^{5} / \mathrm{ml}\right.$ per well) were cultured using a 24-well plate in DMEM containing $10 \%$ FBS and $1 \%$ $\mathrm{P} / \mathrm{S}$ in the absence of $S$. horneri component for 5 days when reached to confluent, and then the cells were cultured in the presence of $S$. horneri component (less than $3000 \mathrm{MW} ; 10,25,50,100$ or $200 \mu \mathrm{g} / \mathrm{ml}$ ) for 2 days. In separate experiments, cells were culture for 5 days without $S$. horneri, and then cells were cultured for 2 days in the presence of S. horneri $(50 \mu \mathrm{g} / \mathrm{ml})$ with or without caspase- 3 inhibitor $(5 \mu \mathrm{M})$. After culture, the cells were detached from each culture dishes and counted [18].

\section{Cell counting}

Cells were detached from each culture dishes using $0.2 \%$ trpysin plus $0.02 \%$ EDTA in $\mathrm{Ca}^{2+} / \mathrm{Mg}^{2+}$-frree PBS for $2 \mathrm{~min}$ at $37^{\circ} \mathrm{C}$, cells were collected after centrifugation [17-19]. Cells were resuspended on PBS solution and stained with eosin. Cell numbers were counted under a microscope using a Hemocytometer plate. For each dish, we took the average of two countings. Cell number showed as number per well of plate.

\section{Statistical analysis}

Data are expressed as the mean \pm standard deviation (SD). Statistical significance was determined using GraphPad InStat version 3 for Windows XP (GraphPad Software Inc. La Jolla, CA). Multiple comparisons were performed by one-way analysis of variance (ANOVA) with Tukey-Kramer multiple comparisons post-test for parametric data as indicated. Data indicated $P<0.05$ was considered statistically significant.

\section{Results}

\section{S. horneri active component suppresses cell proliferation}

Number of human breast cancer MDA-MB-231 bone metastatic cells was increased with periods of culture in the presence of FBS. Presence of $S$. horneri active component (less than MW 3,000; 10-200 $\mu \mathrm{g} / \mathrm{ml}$ ) was found to suppress proliferation in human breast cancer MDA-MB-231 cells cultured for 5 (Figure 1A) and 10 (Figure 1B) days in vitro. Thus, $S$. horneri active component was found to possess suppressive effects on cell proliferation.

Suppressive effects of $S$. horneri active component on proliferation in MDA-MB-231 cells were determined in the presence of various inhibitors that induce cell-cycle arrest in vitro (Figure 2). Cells were cultured for 3 days in the absence (Figure 2A) or presence (Figure 2B) of $S$. horneri active component $(50 \mu \mathrm{g} / \mathrm{ml})$ with or without butyrate (10 and $100 \mu \mathrm{M})$, roscovitine (10 and $100 \mathrm{nM}$ ) or sulforaphane (1 and $10 \mathrm{nM}$ ) [17]. Proliferation of MDA-MB-231 cells was suppressed in the presence of these inhibitors (Figure 2A). Suppressive effects of $S$. horneri active component on cell proliferation were not potentiated in the presence of these inhibitors (Figure 2B).
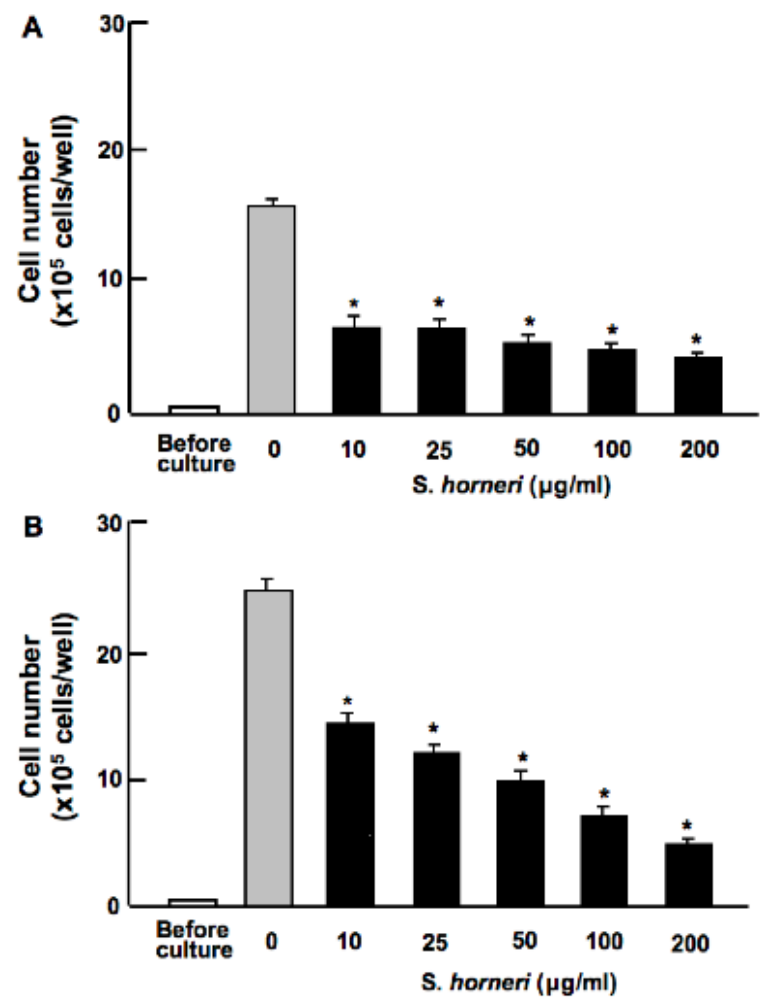

Figure 1. S. horneri active component suppresses proliferation in human breast cance MDA-MB-231 cells in vitro. Cells were cultured in DMEM in the presence or absence of S. horneri active component (less than $3000 \mathrm{MW} ; 10-200 \mu \mathrm{g} / \mathrm{ml}$ ) for 5 (A) or 10 (B) days. After culture, the number of attached cells on dish was counted. Data are presented as mean \pm SD of 2 replicate wells per data set. After culture, the number of attached cells on dish was counted. Data are presented as mean \pm SD of 2 replicate wells per data set using different dishes and cell preparation. ${ }^{*} p<0.001$ versus control (grey bar). 1 way ANOVA, Tukey-Kramer post test. 

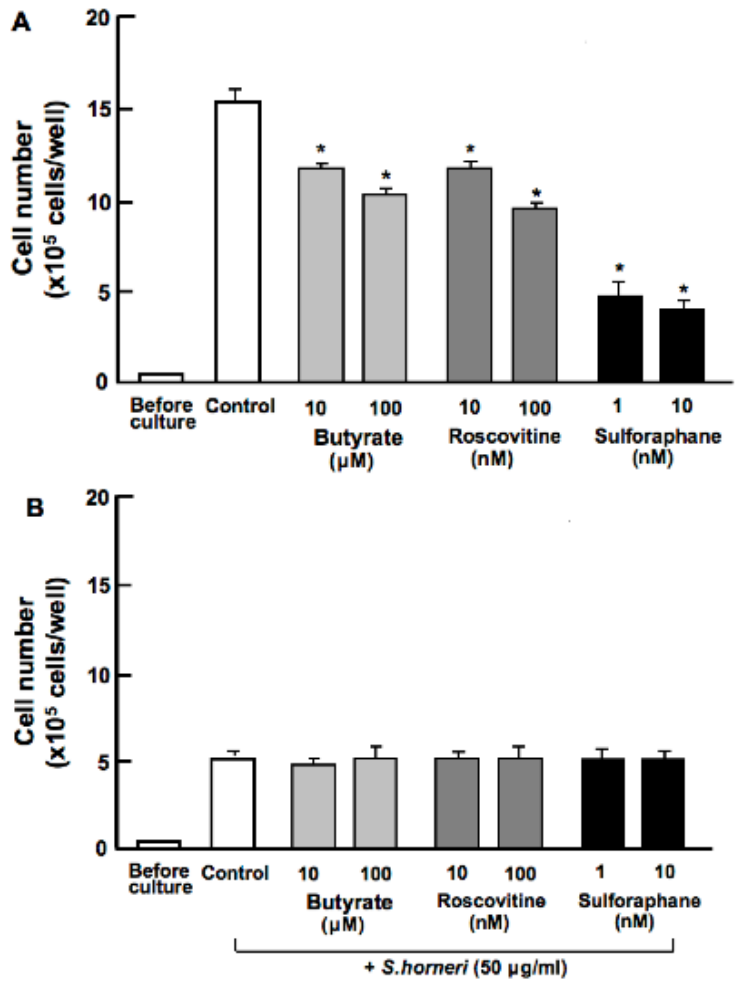

Figure 2. Effect of $S$. horneri active component on proliferation in human breast cancer MDA-MB-231 cells in the presence of various inhibitors that induce cell-cycle arrests in vitro. Cells were culture for 3 days in the absence (A) or presence (B) of $S$. horneri active component (less than $3000 \mathrm{MW} ; 50 \mu \mathrm{g} / \mathrm{ml})$ with or without butyrate $(10$ and $100 \mu \mathrm{M})$, roscovitine (10 and $100 \mathrm{nM}$ ) or sulforaphane (1 and 10nM). After culture, the number of attached cells on dish was counted. Data are presented as mean \pm SD of 2 replicate wells per data set using different dishes and cell preparation. ${ }^{*} p<0.001$ versus control (white bar). 1 way ANOVA, Tukey-Kramer post test.

\section{S. horneri active component stimulates apoptotic cell death}

Human breast cancer MDA-MB-231 cells were cultured for 5 days when reached to confluent, and then the cells were cultured for an additional 2 days in the presence of $S$. horneri active component (less than $3000 \mathrm{MW} ; 10-250 \mu \mathrm{g} / \mathrm{ml}$ ). Cell number was decreased by addition of $S$. horneri active component (Figure 3A). Stimulatory effects of $S$. horneri active component $(25$ or $50 \mu \mathrm{g} / \mathrm{ml}$ ) on cell death in MDA-MB-231 cells were blocked in the presence of caspase-3 inhibitor $(5 \mu \mathrm{M})$ in vitro (Figure $3 \mathrm{~B}$ ). Thus, culture with $S$. horneri active component stimulated apoptotic cell death in breast cancer MDA-MB-231 cells in vitro.

\section{Discussion}

Marine algae S. horneri active component was found to suppress proliferation and stimulate apoptotic cell death in human breast cancer MDA-MB-231 bone metastatic cells in vitro. This finding demonstrates that $S$. horneri possesses an anticancer effect in MDA-MB-231 cells in vitro. This was the first time finding.

Suppressive effects of $S$. horneri active component on cell proliferation in MDA-MB-231 cells may be related to regulation of intracellular signaling pathways in vitro, although anticancer effects of
S. horneri active component are unknown. S. horneri active component has been shown to stimulate osteoblastogenesis and suppress osteoclastogenesis through antagonizing signaling pathway of nuclear factor (NF) $-\kappa B$ in vitro [4]. Signaling of NF- $\kappa B$, which is enhanced in breast cancer cells, has been shown to promote osteolytic bone metastasis by inducing osteoclastogenesis via granulocyte-macrophage colony-stimulating factor (GM-CSF) [20].

Suppressive effects of $S$. horneri active component on proliferation of MDA-MB-231 cells were not seen in the presence of butyrate, roscovitine or sulforaphan that induce cell-cycle arrest. Roscovitine is a potent and selective inhibitor of the cyclin-dependent kinase cdc2, cdk $2 \mathrm{~m}$ and cdk5 [21]. Sulforaphane induces G2/M phase cell cycle arrest [22]. Butyrate induces an inhibition of G1 progression [17]. HCA was suggested to inhibit G1 and G2/M phase cell cycle arrest in MDA-MB-231 cells.

S. horneri active component was found to stimulate apoptotic
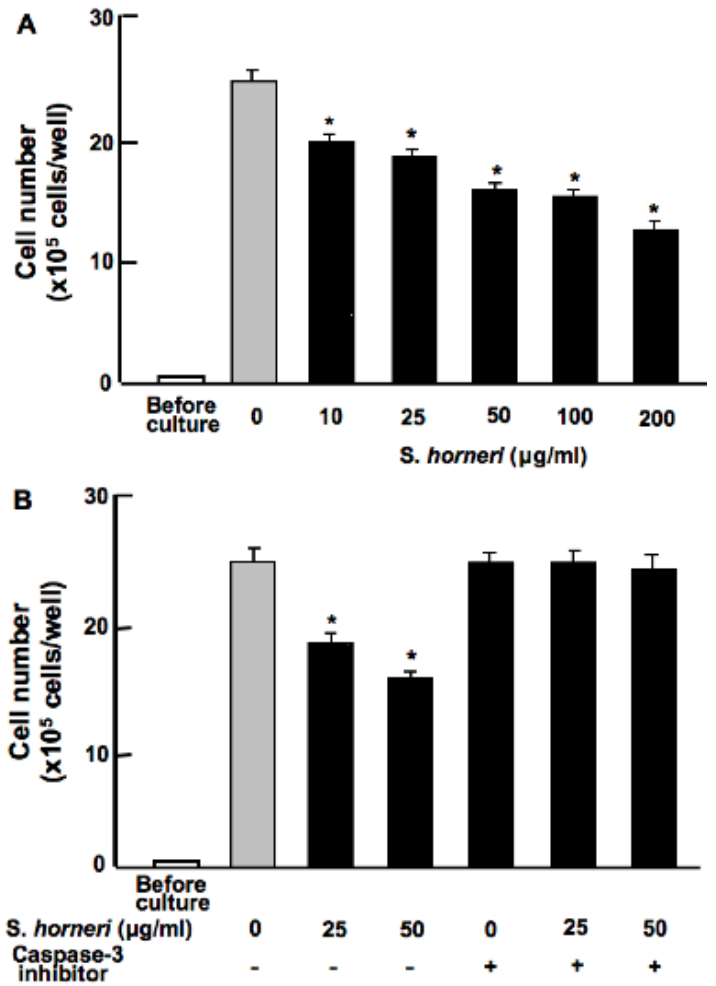

Figure 3. S. horneri active component stimulates apoptotic cell death in human breast cancer MDA-MB-231 cells in vitro. A: Cells were cultured for 5 days when reached to confluent, and then the cells were cultured for an additional 2 days in the presence of $S$. horneri active component (less than $3000 \mathrm{MW} ; 10-250 \mu \mathrm{g} / \mathrm{ml}$ ). B: Cells were cultured for 5 days when reached to confluent, and then the cells were cultured for an additional 2 days in the presence of $S$. horneri active component (less than $3000 \mathrm{MW} ; 25$ or $50 \mu \mathrm{g} / \mathrm{ml}$ ) with or without caspase- 3 inhibitor $(5 \mu \mathrm{M})$. After culture, the number of attached cells on dish was counted. Data are presented as mean $\pm \mathrm{SD}$ of 2 replicate wells per data set using different dishes and cell preparation. ${ }^{*} p<0.001$ versus control (grey bar). 1 way ANOVA, Tukey-Kramer post test. 
Yamaguchi M (2015) Marine algae Sargassum horneri bioactive factor suppresses proliferation and stimulates apoptotic cell death in human breast cancer MDAMB-231 cells in vitro

cell death in MDA-MB-231 cells in vitro. This effect was not seen in the presence of caspase- 3 inhibitor. S. horneri active component may stimulate apoptotic cell death through the mechanism by which increases caspase- 3 activity. It is possible that $S$. horneri active component directly activates caspase- 3 in breast cancer MDA-MB231-cells.

Effective compounds in $S$. horneri active components, which suppress proliferation and stimulate apoptotic cell death in MDAMB-231 cells, have not identified. However, we found the existence of 4 chemicals in S. horneri active components (less than MW 3000) using the analysis with liquid chromatography mass spectrophotometry system (LCMS-IT-TOF; Shimadzu, Kyoto, Japan). These chemicals were identified as 1,3,5-tris(oxolan-2-ylmethyl)-1,3,5-triazinane (MW 339), 5-phenyl-2-[2-(5-phenyltetrazol-2-yl)ethyl]tetrazole (MW 318), 3-(hexadecylamino)propane-1,2-diol (MW 316), and 2-(2-hydroxyethyl-tridecyl-amino)ethanol (MW 288) [23]. These chemicals may possess anticancer effects with either each one or their combination.

S. horneri active component has been shown to possess a stimulatory effect on osteoblastic bone formation and an inhibitory effect on osteoclastic bone resorption in vitro, thereby increasing bone mass [47]. Intake of $S$. horneri extract caused preventive effects on bone loss in osteoporosis animal models and healthy human [8-10]. Functional food factor $S$. horneri extract may be usefulness as an osteogenic factor in preventing osteoporosis in human subjects. Moreover, S. horneri active component is speculated to possess suppressive effects on bone loss induced by breast cancer cell bone metastasis. Intake of $S$. horneri active component may be a useful tool in the prevention and therapy in breast cancer bone metastasis. This remains to be elucidated.

In conclusion, marine algae $S$. horneri active component was found to suppress proliferation and stimulate apoptotic cell death in human breast cancer MDA-MB-231 bone metastatic cells in vitro. Thus, $S$. horneri active component was demonstrated to possess anticancer effects in human breast cancer cells in vitro.

\section{Acknowledgements}

S. horneri extract was supplied through Masaaki Yokoyama, Director, Biomaterial Department, Maruhachi Muramatsu, Inc., Yaizu, Japan.

\section{Author contribution}

The author (M.Y.) contributed to the design and conduct of the study, collection, analysis, and interpretation of data, and manuscript writing. Other authors (T.M.) partly contributed to conduct of the study. All authors have no conflicts of interest.

\footnotetext{
References

1. Sestak I (2014) Preventative therapies for healthy women at high risk of breast 6:423430. [Crossref]

2. Sestak I, Cuzick J (2008) Breast cancer chemoprevention. Oncol Rev 2: 221-226.

3. Yamaguchi M, Hachiya S, Hiratsuka S, Suzuki T (2001) Effect of marine algae extract
}

on bone calcification in the femoral-metaphyseal tissues of rats: Anabolic effect of Sargassum horneri. J Health Sci 4: 533-538.

4. Yamaguchi M, Matsumoto T (2012) Marine algae Sargassum horneri bioactive factor stimulates osteoblastogenesis and suppresses osteoclastogenesis in vitro. $O A$ Biotechnology 1: 3-9.

5. Uchiyama S, Yamaguchi M (2002) Stimulatory effect of Sargassum horneri extract on bone formation in rat femoral-diaphyseal and -metaphyseal tissues in vitro. $J$ Health Sci 48: 148-153

6. Uchiyama S, Yamaguchi M (2002) Inhibitory effect of marine alga Sargassum horneri extract on bone resorption in tissue culture in vitro. J Health Sci 48: 154-160.

7. Uchiyama S, Hashizume M, Hokari Y, Nakagawa T, Igarashi A, et al. (2004) Characterization of active component in marine alga Sargassum horneri extract in stimulating bone calcification in vitro. J Health Sci 50: 634-639.

8. Uchiyama S, Yamaguchi M (2002) Anabolic effect of marine alga Sargassum horneri extract on bone components in the femoral-diaphyseal and -metaphyseal tissues of young and aged rats in vivo. J Health Sci 48: 325-330.

9. Uchiyama S, Yamaguchi M (2003) Preventive effect of marine alga Sargassum horneri extract on bone loss in streptozotocin-diabetic rats in vivo. J Health Sci 49: 149-155.

10. Matsumoto T, Hokari Y, Hashizume M, Yamaguchi M (2008) Effect of Sargassum horneri extract on circulating bone metabolic markers: Supplemental intake has an effect in health humans. J Health Sci 54: 50-55.

11. Mundy GR (2002) Metastasis to bone: causes, consequences and therapeutic opportunities. Nat Rev Cancer 2: 584-593. [Crossref]

12. Roodman GD (2004) Mechanisms of bone metastasis. N Engl J Med 350: 1655-1664.

13. Akhtari M, Mansuri J, Newman KA, Guise TM, Seth P (2008) Biology of breast cancer bone metastasis. Cancer Biol Ther 7: 3-9. [Crossref]

14. Coleman RE (2001) Metastatic bone disease: clinical features, pathophysiology and treatment strategies. Cancer Treat Rev 27: 165-176. [Crossref]

15. Chen YC, Sosnoski DM, Mastro AM (2010) Breast cancer metastasis to the bone: mechanisms of bone loss. Breast Cancer Res 12: 215.

16. Yoneda T, Williams PJ, Hiraga T, Niewolna M, Nishimura R (2001) A bone-seeking clone exhibits different biological properties from the MDA-MB-231 parental human breast cancer cells and a brain-seeking clone in vivo and in vitro. J Bone Miner Res 16: 1486-1495. [Crossref]

17. Yamaguchi M, Daimon Y (2005) Overexpression of regucalcin suppresses cell proliferation in cloned rat hepatoma H4-II-E cells: Involvement of intracellular signaling factors and cell cycle-related genes. J Cell Biochem 95:1169-1177. [Crossref]

18. Izumi T, Yamaguchi M (2004) Overexpression of regucalcin suppresses cell death in cloned rat hepatoma H4-II-E cells induced by tumor necrosis factor-alpha or thapsigargin. J Cell Biochem 92: 296-306. [Crossref]

19. Yamaguchi M, Zhu S, Weitzmann MN, Snyder JP, Shoji M (2015) Curcumin analog UBS109 prevents bone marrow osteoblastogenesis and osteoclastogenesis disordered by coculture with breast cancer MDA-MB-231 bone metastatic cells in vitro. Mol Cell Biochem 401: 1-10. [Crossref]

20. Park BK, Zhang H, Zeng Q, Dai J, Keller ET, et al. (2007) NF-kB in breast cancer cells promotes osteolytic bone metastasis by inducing osteoclastogenesis via GM-CSF. Nat Med 13: 62-69.

21. Palangat M, Grass JA, Langelier MF, Coulombe B, Landick R (2011) The RPB2 flap loop of human RNA polymerase II is dispensable for transcription initiation and elongation. Mol Cell Biol 31: 3312-3325. [Crossref]

22. Meijer L, Borgne A, Mulner O, Chong JP, Blow JJ, et al. (1997) Biochemical and cellular effects of roscovitine, a potent and selective inhibitor of the cyclin-dependent kinases cdc2, cdk2 and cdk5. Eur J Biochem 243:527-536. [Crossref]

23. Yamaguchi M (2013) Marine alga Sargassum horneri component and bone homeostasis Role in osteoporosis prevention. Int J Food Sci Nutr Diet 2:101-109.

Copyright: $₫ 2015$ Yamaguchi M. This is an open-access article distributed under the terms of the Creative Commons Attribution License, which permits unrestricted use, distribution, and reproduction in any medium, provided the original author and source are credited. 